\title{
Life in Code and Digits: When Shannon met Turing
}

\author{
Tula Giannini \\ Dean and Professor \\ School of Information \\ Pratt Institute \\ New York, USA \\ http://mysite.pratt.edu/ giannini/ \\ giannini@pratt.edu
}

\author{
Jonathan P. Bowen \\ Professor of Computing \\ School of Engineering \\ London South Bank University \\ London, UK \\ http://www.jpbowen.com \\ jonathan.bowen@/sbu.ac.uk
}

\begin{abstract}
Claude Shannon (1916-2001) is regarded as the father of information theory. Alan Turing (19121954 ) is known as the father of computer science. In the year 1943, Shannon and Turing were both at Bell Labs in New York City, although working on different projects. They had discussions together, including about Turing's "Universal Machine," a type of computational brain. Turing seems quite surprised that in a sea of code and computers, Shannon envisioned the arts and culture as an integral part of the digital revolution - a digital DNA of sorts. What was dreamlike in 1943 , is today a reality, as digital representation of all media, accounts for millions of "cultural things" and massive music collections. The early connections that Shannon made between the arts, information, and computing, intuit the future that we are experiencing today. This paper considers foundational aspects of the digital revolution, the current state, and the possible future. It examines how digital life is increasingly becoming part of real life for more and more people around the world, especially with respect to the arts, culture, and heritage.
\end{abstract}

Computer science. Information theory. Digital aesthetics. Digital culture. GLAM.

\section{INTRODUCTION}

"I can visualize a time in the future when we will be to robots as dogs are to humans. [...] I am rooting for the machines!" - Claude Shannon (Liversidge 1987).

We can trace the beginning of the digital revolution (Negroponte 1995) back to the 1940s, when Claude Shannon (James 2009, Soni \& Goodman 2017), at age 32, introduces what he calls, "information theory" in his paper, A Mathematical Theory of Communication (Shannon 1948). A momentous work that spawns technological innovation, the paper establishes that all modes of communication, and all media can be expressed in code as binary digits or bits and transmitted error free. The inseparable connection between digital information and communication that Shannon describes anticipates a digital future of profound change that ties to the foundational concepts and architecture of the Internet and the Web.

Also in 1948, intersecting with Shannon's pioneering theory, Alan Turing (Bowen 2012 \&
2016, Copeland et al. 2017), considered the father or founder of computer science (Bowen 2017), then aged 36, writes a report at the National Physical Laboratory on "Intelligent Machinery" (Turing 1948, also published 20 years later in 1968), that lays the groundwork for the emerging fields of connectionist networks and artificial intelligence (Copeland \& Proudfoot 1999, Copeland 2017).

The work of these two great scientists comes together when computing moves from analogue to digital (Bowen \& Giannini 2016), adopting Shannon's universal binary language of ones and zeroes, while building on Turing's codebreaking work based on the "bombe", the name of an electro-mechanical computing device used for breaking the German Enigma during World War II. These developments have led to the life-changing and ubiquitous fusion of information, communication, and computing, which today has reached a tipping point of sorts that is often referred to as the Internet of Things (IoT), but in reality is more like the "Internet of Life" (loL), connecting people as well as devices. 
Since 1948, we have witnessed a steady progression of developments by which analogue technologies have gone digital, including in the arts (Bowen \& Giannini 2016), with fundamental developments in photography, sound recording, film, video, radio, television, and telephone technology, in an increasingly mobile world (Filippini-Fantoni \& Bowen 2008). Concurrently, we are experiencing a stream of digital transformations across human activity and interaction (Bowen \& Giannini 2014). As daily life moves towards total immersion in the digital environment, a new digital way of life is emerging that in turn is causing a dramatic shift whereby digital dominates information behaviour, alters aesthetic perceptions (Hoy 2010), and recasts seeing and human expression within digital modes (Giannini \& Bowen 2016).

Our study looks at looks at this digital phenomenon and how it is radically changing the arts and cultural landscape, disrupting social order and recasting cultural norms in unforeseen ways. As real and virtual life evolve into a fused experience, we aim to explore and digitally capture the effects of life in code and digits set at the intersection of digital information, communication, and computing, as we gratefully acknowledge the pioneering work of Claude Shannon and Alan Turing (see Figure 1).

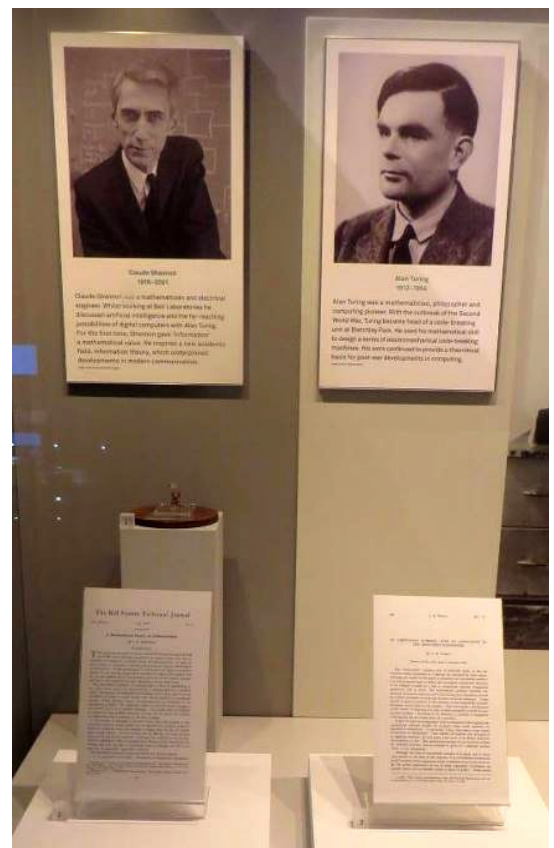

Figure 1: Shannon and Turing display with seminal papers in the Information Age gallery at the Science Museum, London (Blyth 2014). (Photograph by J. P. Bowen.)

\section{Theoretical love (by T. Giannini)}

When Shannon met Turing

Computing

fell in love

with digital information

\begin{abstract}
A transformation
A revolution

New computations

Sparking innovations
\end{abstract}

When Shannon met Turing

a moment enduring

Alluring algorithms

touched information theorems

Analogue meets digital

Goodbye physical

Snapshots of the past

Silos can't last

Connecting digital dots

Bits and bots

\section{THE SCIENCE OF DIGITAL CULTURE}

\subsection{Shannon and Turing}

There are parallels in the work of Claude Shannon and Alan Turing, as illustrated by the fact that they are on display together in the Information Age exhibition (Blyth 2014) at the Science Museum in London (see Figure 1). Both produced foundational work for computer science in the related areas of information and computation theory (Dasgupta 2016).

In 1936, Turing, aged 24, published his highly innovative paper on the fundamental nature of computation through his theoretical concept of what has become known as a Turing machine (Turing 1936). In 1937, Shannon, as a master's student at Massachusetts Institute of Technology (MIT) and aged only 21, demonstrated in his master's thesis that Boolean algebra could be used to construct any desired logical/numerical relationship in the context of electrical digital circuit design theory (Shannon 1937). An associated journal paper appeared a year later (Shannon 1938).

Turing undertook his $\mathrm{PhD}$ at Princeton University in the USA during 1936-38, taking only a year and nine months to complete it (Turing 1938). Towards the end of this time, he also worked on an electronic cipher machine. Meanwhile, Shannon worked on his $\mathrm{PhD}$ at MIT, achieving it in 1940 (Shannon 1940). By this time, Turing had returned to the UK before the start of World War II. In the same year, Shannon joined the Institute for Advanced Study at Princeton University as a National Research Fellow, sadly not overlapping with Turing's time there.

Both Shannon and Turing worked on cryptanalysis during WW II, for the USA and UK respectively. Shannon worked at Bell Labs in New York from 1941, whereas from 1939 Turing was based in the English countryside at Bletchley Park, the UK wartime codebreaking centre. 
In early 1943, during World War II, Alan Turing travelled to Bell Labs, then based in Greenwich Village, Manhattan, New York, for two months, working on speech encryption. Turing would probably have found Greenwich Village in 1943 more exciting than Princeton in the late 1930s, with its sexual casualness even then. He once said "I've spent a considerable time on your subway. I met someone who lived in your Brooklyn who wanted me to play Go." (Hodges 1983, p. 249).

At Bell Labs, the American William Friedman was the chief cryptanalyst and thus officially held Turing's equivalent position in the US. Friedman was older and more old fashioned than Turing, being much more concentrated on codes and cyphers compared to the wider interests of Turing. However, Turing had tea in the Bell Labs cafeteria each day (Cobb 2015). Here he met an academic and philosophical engineer, namely Shannon, and the two had much in common. Turing and Shannon recognised each other's intellectual depth. Where Turing had precisely defined the notion of a computing machine mathematically (Turing 1936), Shannon had similar insights into the nature of communication and information (Shannon 1948, 1949). Note that the 1949 paper was originally submitted in 1940 (Hodges 1983, p. 552).

Turing's strength was the logic of machines, with an interest in information theory, which complemented Shannon's strengths. Turing's concept of a "deciban" was very similar to Shannon's measure for information (cf. "decibel", named in honour of Alexander Graham Bell). Shannon coined the term "bit" in Shannon (1948) and the term "Shannon" is also sometimes used in information theory in homage to Shannon. The terms "ban" and "deciban" were introduced by Turing (with Jack Good) in 1940 as an information measure for the weight of evidence in the Banburismus procedure used at Bletchley Park for cryptanalysis (Copeland et al. 2017, pp. 421-2). There are significant parallels in Turing's and Shannon's treatment of information.

With respect to computation, Shannon had worked on the differential analyser at MIT designed by Vannevar Bush in 1930 and had designed a logical relay machine himself (Shannon 1938), written in 1937 at the same time that Turing was working on an electric multiplier at Princeton. Turing showed his 1936 paper on computable numbers (Turing 1936) to Shannon, who was impressed by the ideas in the paper. Shannon believed that a machine should be able to imitate the workings of the brain and this was in tune with Turing's thinking too. (Blyth 2014, pp. 15, 20). Turing said "Shannon wants to not just feed data to a Brain, but cultural things! He wants to play music to it!" (Hodges 1983, p . 251), understandably as Shannon loved Dixieland jazz throughout his life (Cobb 2015).
With their interest in machine intelligence, both Shannon and Turing worked on computer chess as a problem that required "thinking" to demonstrate skilful play (Copeland et al. 2017, pp. 344-6). It is quite possible that Turing discussed this with Shannon at Bell Labs since he had already expounded his ideas to Jack Good and Donald Mitchie in England. In 1948, Turing and David Champernowne produced a chess-playing program call "Turochamp" (Copeland 2004, pp. 562-4), while Shannon (1950) also independently considers programming a computer to play chess. More recently, computers have exceeded the best human chess players with IBM's Deep Blue computer program beating Garry Kasparov in a sixgame match in 1997 (Copeland et al. 2017, pp. 327-9).

In any case, the discussions between Shannon and Turing may well have developed Turing's thoughts on machine intelligence, later dubbed "Artificial Intelligence" (Al). This led to Turing's philosophical paper Computing machinery and intelligence (Turing 1950), where he described what later became known as the "Turing test", an experiment to demonstrate machine intelligence that is still relevant today.

Shannon's interest in Turing's ideas continued after Turing's untimely death in 1954. Shannon \& McCarthy (1956) proposed the Shannon-McCarthy Objection regarding the Turing test, where a very large yet finite look-up table could be used to generate human-like responses (Copeland 2004, pp. 436-8). In the same year, Shannon also demonstrated that two symbols (e.g., 0 and 1) are all that are required for a Turing machine (Wolfram 2002, p. 1119).

\subsection{History of the New York Bell Labs Building}

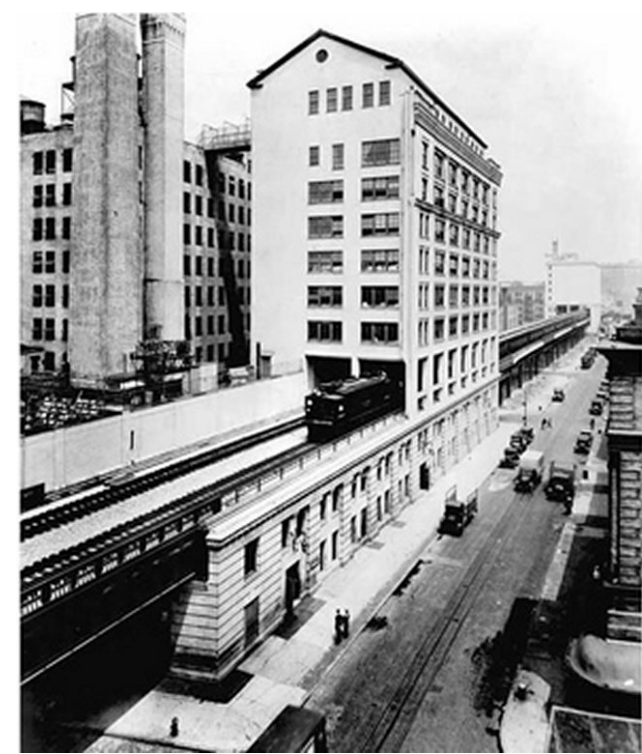

Figure 2: Bell Laboratories building in Manhattan, New York, 1936. (Wikimedia Commons.) 
The main Bell Labs building in Manhattan where Shannon and Turing both worked in 1943 was over the elevated West Side Line (popularly known as the "High Line", now disused), which passed through the building (see Figure 2). The Greenwich Village locale is known as a hub for artists and the LGBT community, which Turing is likely to have appreciated. Bell Labs moved from the building in 1966 and established its headquarters in Murray Hill, New Jersey.

Experiments in Art and Technology (E.A.T.) was a non-profit and tax-exempt organisation established in 1967 to develop collaborations between artists, such as Robert Rauschenberg (1925-2008) and John Cage (1912-1992), with engineers at Bell Labs.

The Manhattan building was bought by Westbeth in 1967 and, after renovation, the building reopened in 1970 as a complex of affordable facilities including housing and studios for artists and arts organisations. The building was declared as a US National Historic Landmark in 1975 and added to the US National Register of Historic Places. The High Line was discontinued in 1980, although part of it north of the building is now an elevated walkway and park, with the newly moved Whitney Museum at its southern end.

\subsection{Turing and Warhol}

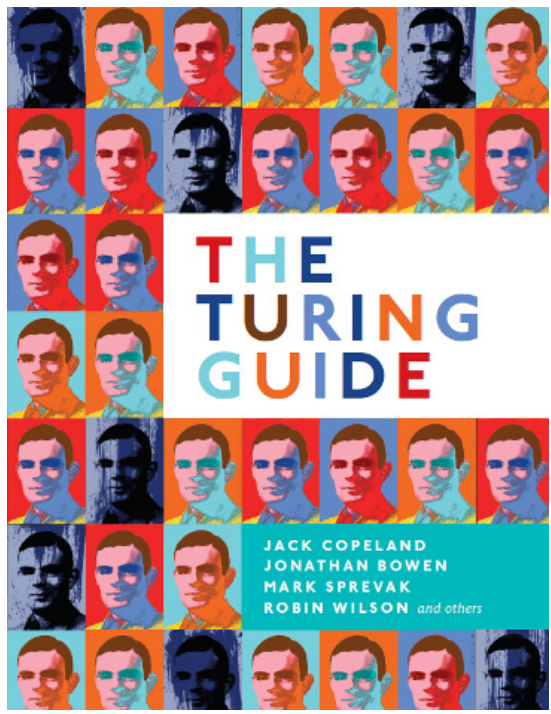

Figure 3: Analogue art goes digital: cover for The Turing Guide (Copeland et al. 2017).

If Turing had been born a decade or two later and visited New York, it is interesting to speculate whether he could have met Andy Warhol (19281987) at The Factory, Warhol's studio and LGBT social hub at various locations in Manhattan. Of course, Turing's importance was unknown to Andy Warhol due to the secrecy surrounding Turing's wartime work. Had he known of Turing's historical role and early death by probable suicide (aged 41), perhaps he would have been inspired to produce similar multiple screen-print portraits of Turing to those he did of Marilyn Monroe (1926-1962), who also died tragically young (aged 36) and of likely suicide, but with conspiracy theories also proposed too. These thoughts inspired the cover for a recent book on Turing's life and work (see Figure 3), including some of his interactions with Shannon (Copeland et al. 2017).

\subsection{Recent Developments}

Artificial Intelligence has been slow in coming, but has seen a recent boost with advances in the concept of "deep learning", a form of unsupervised machine learning. Al techniques can give computers a level of expertise considered on a par with or greater than the power of the best humans in limited domains, such as chess and more recently the ancient Chinese board game Go. However, enabling a computer to develop expertise in multiple games, for example, as proved much more difficult.

More serious recent $\mathrm{Al}$ applications include, for example, computer-based search for cancer treatments (Mukherjee 2016), scanning through massive amounts of data in an intelligent manner. Although machines are not yet more intelligent than humans, that possibility is still a very real one in the future (Bostrom 2014). Scientifically, the influence of Shannon and Turing continues to this day through their foundational work on computation, information, and $\mathrm{Al}$, and is likely to continue.

\section{MANIFESTATIONS OF DIGITAL ART \& LIFE}

\subsection{Education}

Over the past few years and still continuing, the dramatic changes in the integration of the fields of information and computing, often using visualisation techniques (McCandless 2012, Rendgen \& Wiedemann 2012), higher education schools that were founded originally as schools of library science, have transformed into schools of information, whilst some have become schools of computing and information. The dominant driver of today's changing educational landscape grows out of the information field's recognition of the inseparable nature of information, communication, and computing, and that is manifest in the structure and function of the Internet and Web, together with the tools and digital technologies that propel the loT and innovation and development across disciplines from the sciences to arts and humanities.

Some recent examples in the US that reflect the information field in rapid transformation are Drexel, Indiana and Pittsburgh Universities and Pratt Institute. Pittsburgh's School of Information Sciences is being replaced with a newly 
established School of Computing and Information to launch in July 2017 (University of Pittsburgh 2016), echoing the idea that one can no longer separate computing and information, the pillars of the digital age in education, human interaction, and user experience, driven by digital convergence across all major media. Pratt's transformation to a school of information is distinguished by its context in the arts, culture, and technology, set in New York City and reflected in its three new masters of science degrees: Museums and Digital Culture, Information Experience Design, and Data Analytics and Visualization.

These new directions in education for the information field reflect the work and vision of Shannon and Turing, which only now, almost 70 years later, is becoming more fully realised.

\subsection{Digital Seeing and Aesthetics - from MoMA to Saks}

The New York City digital experience is growing dramatically particularly at museums and retail stores. Visiting the shops at Columbus Circle (see Figure 4), the galleries of the Museum of Modern Art (MoMA) on $53^{\text {rd }}$ Street, and retail stores near MoMA on Fifth Avenue (for example, Oakley, Saks $5^{\text {th }}$ Ave., and Hollisters), present onlookers with digital works that offer new ways of seeing through a plethora of digital media displays and installations that no doubt influence their perceptions of what is art.

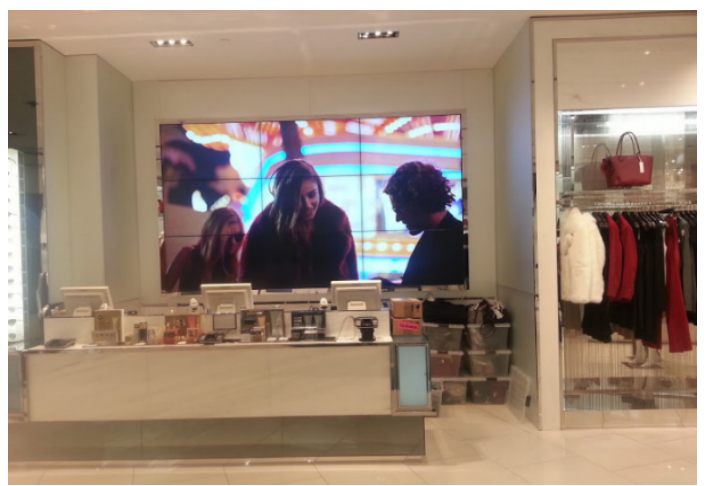

Figure 4: Newly installed screens in shops at Columbus Circle, W. $59^{\text {th }}$ St., New York.

(Photograph by T. Giannini.)

The entire ceiling of the edgy sports store, Oakley, is illuminated by a series of interactive media screens (see Figure 5). Designed by Moment Factory as a permanent installation, it harks back to the painted ceilings of the $18^{\text {th }}$ century, whilst adding interaction and motion graphics.

The windows of Saks are taken up by a sequence of digital displays that change rapidly in unison and flash texts such as feminism and revolution. Figure 6 shows Saks windows when it was displaying the first two letters of the perfume, "J'ADORE".

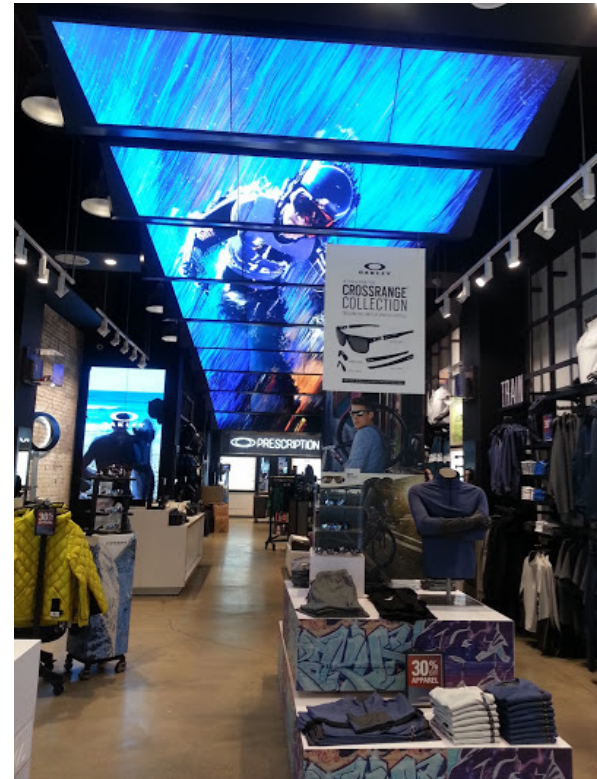

Figure 5: Oakley retail sports on Fifth Avenue. The ceiling is designed by Moment Factory as a permanent digital installation.

(Photograph by T. Giannini.)

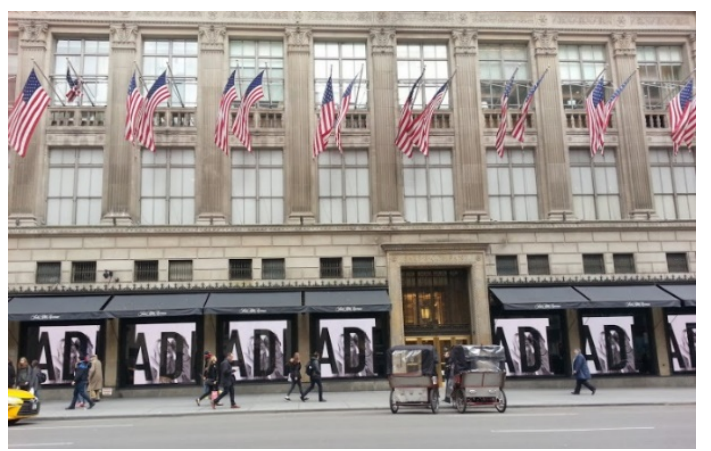

Figure 6: Saks $5^{\text {th }}$ Ave., New York, digital media windows and passers-by. (Photograph by T. Giannini.)

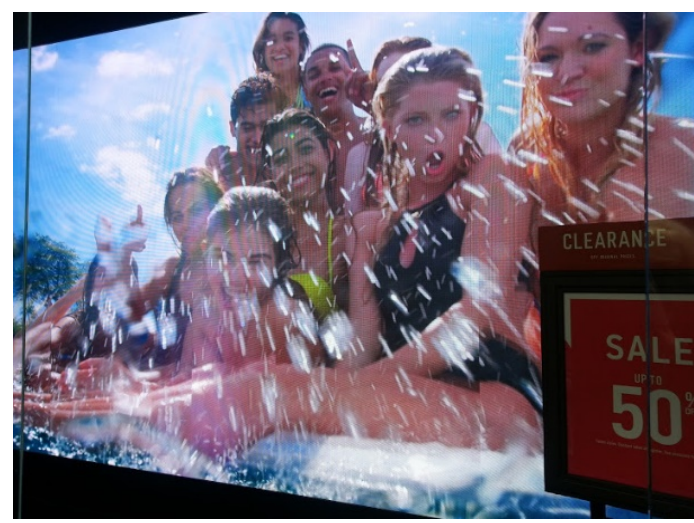

Figure 7: Digital display with music at entrance to Hollister retail store at $5^{\text {th }}$ Ave. and $46^{\text {th }}$ St., New York. (Photograph by T. Giannini.)

Proceeding downtown, to $46^{\text {th }}$ and Fifth Ave., Hollister, a clothing store with a Southern California aesthetic aimed at the 18-30 age group, grabs attention with a digital media display and audio 
surrounding its entrance (see Figures 7 and 8). The digital work focuses on beach scenes and water splashing making surprising connection to David Hockney's Hollywood swimming pools.

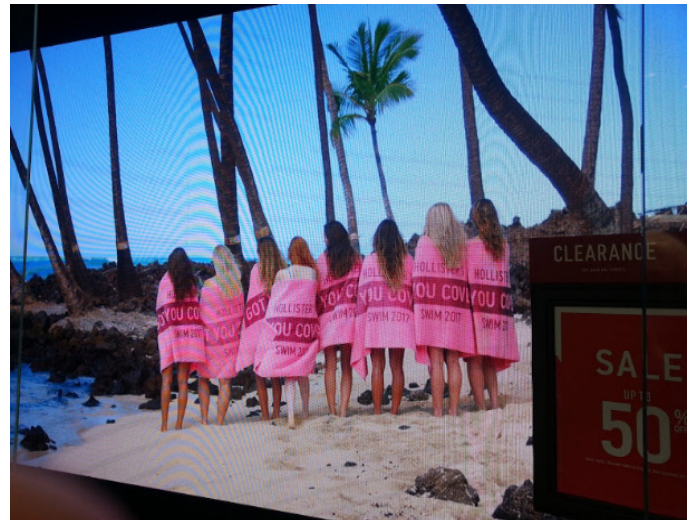

Figure 8: $L A$ beach, large digital screen at entrance to Hollister. The images change every few seconds. (Photograph by T. Giannini.).

\subsection{Reading Digital}

A study by Pew Research shows that reading on the Internet is preferred by young readers. "Most of that reading among younger adults is through digital text rather than print. About eight-in-ten (81\%) of 18- to 29 -year-olds who prefer to read their news also prefer to get their news online; just $10 \%$ choose a print newspaper." (Mitchell 2016). The breakdown among 30- to 49-year-olds is similar.

\subsection{Digital Communication - When Media and Message are Digital}

When Shannon and Turing were at Bell Labs in New York City at 463 West Street (see Figure 2), in 1943, they would meet for tea. Their discussion focused mostly on computing and the brain, artificial intelligence and machine learning, all of which are still highly pertinent today.

Digital communication, which now occupies the lion's share of human activity, is advancing into new territory. Humans are beginning to relate to robots in new ways as seen in Spillikan - A Love Story, a new play touring the United Kingdom during 2016-2017 including London, in which "RoboThespian" (Engineered Arts 2014, Hickey 2014) - a life sized humanoid robot designed for human interaction, including kissing - plays a lead role in this stage production (Reuters 2017). How much can humans love digital things and what happens when human/robot relationships replace human to human relationship as humans fall in love with robots.

\section{CONCLUSION}

The reputations of Shannon and Turing have changed considerably over time. Scientists recognised their stature early. For example, they are the only two scientists to be mentioned in von Neumann (1958) (Copeland 2004, p. 22). Wartime secrecy mean that knowledge of Turing's importance was considerably delayed in popular circles. For example, a 1965 book on mathematics for general readership mentioned Shannon with an accompanying full-page photograph (Bergamini 1965 , pp. 50-1), whereas there is no mention of Turing. In 2012, Turing was selected as one of 43 people considered as the top scientists of all time (Bowen 2012), with no mention of Shannon. On the other hand, in the same year, Shannon's information equation was selected as one of 17 equations that have dramatically affected the world (Stewart 2012). Shannon's analysis led to a formula as follows. For two symbols (e.g., 0 and 1, as in a bit), with probability $p$ and $q$ respectively (i.e., $q=1-p$ ), then the information content in a message $H$ can be given as (Stewart 2012, p. 273):

$$
H=-p \log p-q \log q
$$

where $\log$ is the base 2 logarithm. This can be generalised to (Stewart 2012, p. 265):

$$
H=-\sum_{x} p(x) \log p(x)^{\text {tl }}
$$

where $p(x)$ is the probability of a symbol $x$ occurring in a message.

In 2016, both Shannon and Turing have their rightful place in the Oxford Dictionary of Computer Science (Butterfield \& Ekembe 2016) with five Shannon-related entries and five Turing-related entries, illustrating their importance for the foundations of computer and information science.

Horst Feistel, an IBM mathematician, said of Shannon in 1973 that his work "opened up almost unlimited possibilities to invention, design and research" (Rooney 2016, p. 41). Turing has been similarly lauded for his contribution to computer science. Together they are giants of the foundational aspects of computation and information theory, enabling the digital world in which we now live, sometimes dubbed the "Information Age" (Blyth 2014, Copeland 2012, Soni \& Goodman 2017).

Today, communication is dominated by digital media conveyed by emails, text, images, video, and sound, so that media, message, and meaning, are digital and integrated. This convergence is changing how we interpret the message, whether we see it as art or information, and how we assign it aesthetic value.

Examples of this were on view in MoMA's digital lobby exhibit, Inbox: New Acquisitions by Shigetaka Karita in 1999, featuring her emoji designs, which according to MoMA "planted the seeds for the explosion of a new visual language" and "facilitated 
the rise of nascent practices of text messaging and mobile email" (MoMA's display text, see Figure 9).

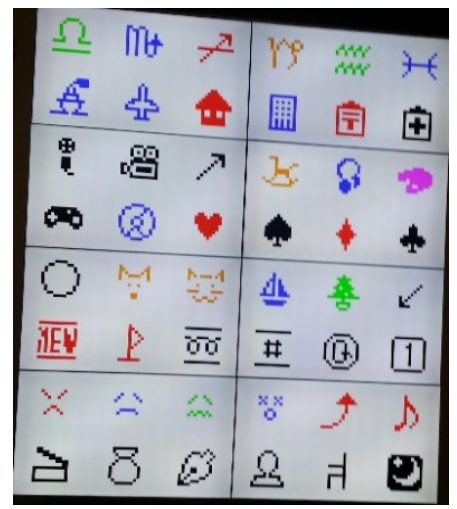

Figure 9: "Inbox", by Shigetaka Karita, 1999 digital emoji designs. (Photograph by T. Giannini.)

A digital work of 2012 at the Tate Modern, by Angela Bullock, entitled, Aluminium 4, is described on its accompanying label as, "4 aluminium pixel boxes with DMX [Digital Multiplex] control box, lighting system, electrical components and cable" (see Figure 10). The boxes, each having a different colour screen, are programmed to change colour and be interactive with viewers.

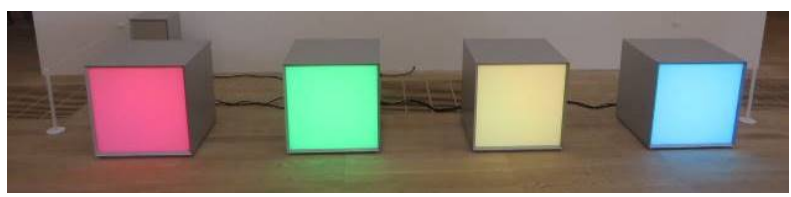

Figure 10: "Aluminium 4", by Angela Bullock, 2012 exhibit at Tate Modern. (Photograph by J. P. Bowen.)

As the opposition of physical or digital as two distinct states of being fades, and becomes increasingly inextricably linked and indiscernible, we find ourselves living in a new digital reality, unsure of how coded digital life will reflect our human and artistic values.

Despite the huge scientific contributions of Shannon and Turing, both if briefly together at Bell Labs in Manhattan during 1943, there is no memorial to either of them in New York City (Hargittai \& Hargittai 2017). This is an omission that both authors would love to see rectified in the digital years to come.

\section{Message me when (by T. Giannini)}

\author{
The message \\ The meaning \\ Identities beaming \\ Data streaming \\ We're connected \\ My digital life \\ Perfected \\ Physical life \\ Undirected
}

\author{
Everything coded \\ Life eroded \\ Just dreaming \\ Beam me down \\ We'll hang around \\ A message received \\ Not retrieved \\ I believe \\ It was you
}

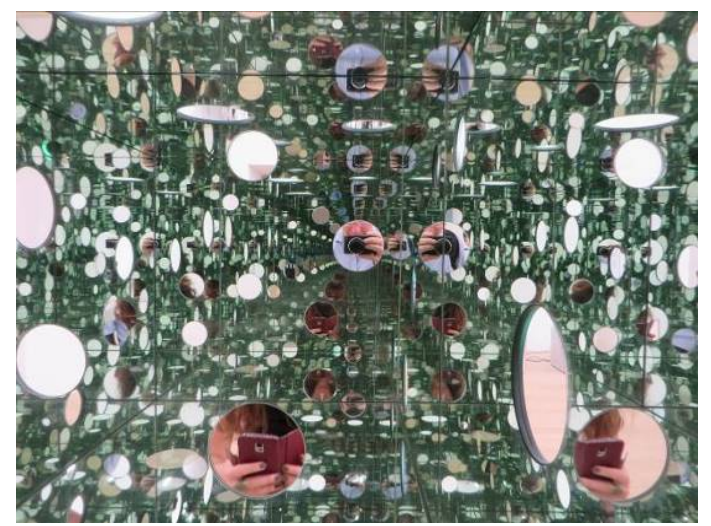

Figure 11: Internal view of "The Passing Winter", by Yayoi Kusama, 2005. The infinite possibilities of digital life in an analogue world - exhibit at Tate Modern. (Photograph by J. P. Bowen.)

\section{Acknowledgement}

Jonathan Bowen is grateful to Museophile Limited for financial support.

\section{REFERENCES}

Bergamini, D. (1965) Mathematics. Life Science Library, Time-Life International.

Blyth, T. (ed.) (2014) Information Age: Six networks that changed the world. Scala Arts \& Heritage Publishers.

Bostrom, N. (2014) Superintelligence: Paths, Dangers, Strategies. Oxford University Press.

Bowen, J. P. (2012) Alan Turing. In A. Robinson (ed.), The Scientists: An Epic of Discovery. Thames and Hudson, pp. 270-275.

Bowen, J. P. (2016) Alan Turing: Virtuosity and visualisation. In Bowen et al. (2016), pp. 197-204. DOI: 10.14236/ewic/EVA2016.40

Bowen, J. P. (2017) Alan Turing: Founder of Computer Science. In J. P. Bowen, Z. Liu, and Z. Zhang (eds.), Engineering Trustworthy Software Systems: Second International School, SETSS 2016, Chongqing, China, March 28 - April 2, 2016. Springer, LNCS, vol. 10215, pp. 1-15. DOI: 10.1007/978-3-319-56841-6 1

Bowen, J. P., Diprose, G., and Lambert, N. (eds.) (2016) EVA London 2016: Electronic Visualisation and the Arts. BCS, eWiC. http://www.bcs.org/ewic/eva2016

Bowen, J. P. and Giannini, T. (2014) Digitalism: the new realism? In K. Ng, J. P. Bowen, and S. McDaid (eds.), EVA London 2014: Electronic Visualisation and the Arts. BCS, eWiC, pp. 324-331. DOI:10.14236/ewic/eva2014.38 
Bowen, J. P. and Giannini, T. (2016) From analogue to digital in literature and art. In Bowen et al. (2016), pp. 14. DOI: $10.14236 /$ ewic/EVA2016.1

Butterfield, A. and Ekembe, G. (eds.) (2016). A Dictionary of Computer Science, $7^{\text {th }}$ edition. Oxford University Press.

Cobb, M. (2015) Life's Greatest Secrets: The Race to Crack the Genetic Code. Profile Books.

Copeland, B. J. (ed.) (2004) The Essential Turing. Oxford University Press.

Copeland, B. J. (2012) Turing: Pioneer of the Information Age. Oxford University Press.

Copeland, B. J. (2017) Intelligent machinery. In Copeland, et al. (2017), chapter 25, pp. 265- 275.

Copeland, B. J., Bowen, J. P., Sprevak, M., Wilson, R. J., et al. (2017) The Turing Guide. Oxford University Press. http://tinyurl.com/TheTuringGuide

Copeland, B. J. and Proudfoot, D. (1999) Alan Turing's forgotten ideas in computer science. Scientific American, 280, pp. 99-103, April.

Dasgupta, S. (2016) Computer Science: A Very Short Introduction. Oxford University Press.

Engineered Arts (n.d.) RoboThespian. Engineered Arts, UK. https://www.engineeredarts.co.uk/robothespian/ (accessed 4 April 2017).

Filippini-Fantoni, S. and Bowen, J. P. (2008) Mobile multimedia: Reflections from ten years of practice. In L. Tallon and K. Walker (eds.) Digital Technologies and the Museum Experience. AltaMira, pp. 79-96.

Giannini, T. and Bowen, J. P. (2016) Curating digital life and culture: Art and information. In Bowen et al. (2016), pp. 237-244. DOI: 10.14236/ewic/EVA2016.46

Hargittai, I. and Hargittai, M. (2017) New York Scientific: A culture of inquiry, knowledge, and learning. Oxford University Press.

Hickey, S. (2014) RoboThespian: The first commercial robot that behaves like a person. The Guardian, 17 August.

https://www.theguardian.com/technology/2014/aug/17/robothespianengineered-arts-robot-human-behaviour (accessed 10 April 2017).

Hodges, A. (1983/2012) Alan Turing: The Enigma, Simon and Schuster / Princeton University Press.

Hoy, M. A. (2010) From Point to Pixel: A Genealogy of Digital Aesthetics. Electronic Theses and Dissertations, University of California Berkeley, USA.

http://escholarship.org/uc/item/25f4v730 (accessed 3 January 2017).

James, I. (2009) Claude Elwood Shannon 30 April 1916 - 24 February 2001. Biographical Memoirs of Fellows of the Royal Society, 55, pp. 257-265. DOI: 10.1098/rsbm.2009.0015

Liversidge, A. (1987) Profile of Claude Shannon. Omni, pp. 64,66 , August.

Mitchell, A. (2016) Younger adults more likely than their elders to prefer reading news. Pew Research Center, 6 October. http://www.pewresearch.org/facttank/2016/10/06/younger-adults-more-likely-than-their-elders-toprefer-reading-news/ (accessed 4 April 2017).

McCandless, D. (2012) Information is Beautiful. Collins.
Mukherjee, S. (2016) IBM Workers to Use Watson Supercomputer to Find Cancer Treatments. Fortune, 11 October. http://fortune.com/2016/10/11/ibm-watson-empoyeescancer-drugs/ (accessed 5 April 2017).

Negroponte, N. (1995) Being Digital. Hodder \& Stoughton.

Rendgen, S. and Wiedemann J. (ed.) (2012) Information Graphics. Taschen.

Reuters (2017) A robot-actor stuns London audiences in a new play. Reuters, 13 March.

http://www.reuters.com/video/2017/03/13/a-robot-actor-stuns-londonaudiences-in?videold=371294101 (accessed 4 April 2017).

Rooney, D. (2016) Mathematics: How it shaped our world. Scala Arts \& Heritage Publishers.

Shannon, C. E. (1937) A Symbolic Analysis of Relay and Switching Circuits. Master's thesis, Department of Electrical Engineering, Massachusetts Institute of Technology, USA, 10 August.

http://dspace.mit.edu/bitstream/handle/1721.1/11173/34541425MIT.pdf (accessed 4 April 2017).

Shannon, C. E. (1938). A symbolic analysis of relay and switching circuits. Transactions of the American Institute of Electrical Engineers, 57(12), pp. 713-723. DOI: 10.1109/T-AIEE.1938.5057767

Shannon, C. E. (1940) An Algebra for Theoretical Genetics. PhD thesis, Department of Mathematics, Massachusetts Institute of Technology, USA. http://hdl.handle.net/1721.1/11174 (accessed 4 April 2017).

Shannon, C. E. (1948) A mathematical theory of communication. The Bell System Technical Journal, 27, pp. 379-423, 623-656, July, October. DOI: 10.1002/j.1538-7305.1948.tb01338.x

Shannon, C. E. (1949) Communication in the presence of noise. Proceedings of the IRE, 37(1), pp. 10-21, January. DOI: 10.1109/JRPROC.1949.232969

Shannon, C. E. (1950) Programming a computer for playing chess. Philosophical Magazine, 41, pp. $256-275$.

Shannon, C. E. and McCarthy, J. (eds.) (1956) Automata Studies. Princeton University Press.

Soni, J. and Goodman, R. (2017) A Mind at Play: How Claude Shannon Invented the Information Age. Simon \& Schuster.

Stewart, I. (2012) Codes, communications, and computers: Information theory, chapter 15, pp. 265-282. In 17 Equations that Changed the World. Profile Books.

Turing, A. M. (1938) The purpose of ordinal logics. In Systems of logic based on ordinals: a dissertation. PhD thesis, Princeton University, USA.

Turing, A. M. (1948) Intelligent Machinery. Report, Mathematics Division, National Physical Laboratory, UK. http://www.alanturing.net/intelligent_machinery/

Turing, A. M. (1950) Computing machinery and intelligence. Mind, 59(236), pp. 433-460, October. DOI: 10.1093/mind/LIX.236.433

University of Pittsburgh (2016) School of Computing and Information. YouTube, 28 October.

https://www.youtube.com/watch?v=2ib9vPA8kys (accessed 30 March 2017).

von Neumann, J. (1958), The Computer and the Brain. Yale University Press.

Wolfram, S. (2002) A New Kind of Science. Wolfram Media. 